\title{
Effect of Pseudomonas Elastase on Human Mononuclear Phagocyte $\alpha_{1}$-Antitrypsin Expression
}

\author{
CHARLOTTE BARBEY-MOREL AND DAVID H. PERLMUTTER
}

Departments of Pediatrics, Cell Biology, and Physiology, Washington University School of Medicine, and Divisions of Infectious Diseases, Gastroenterology, and Nutrition, Children's Hospital, St. Louis, Missouri 63110

\begin{abstract}
The net balance of neutrophil elastase and its inhibitor, $\alpha_{1}$-antitrypsin $\left(\alpha_{1}\right.$-AT), is a critical determinant of connective tissue turnover during homeostasis and in disease states. In addition to liver-derived $\alpha_{1}$-AT, which translocates from blood to tissues, this elastase- $\alpha_{1}-\mathrm{AT}$ balance is maintained by expression of $\alpha_{1}$-AT at the local tissue level in resident mononuclear phagocytes. Our previous studies have shown that this elastase- $\alpha_{1}-\mathrm{AT}$ balance is also tightly controlled at a cellular level in that addition of exogenous neutrophil elastase (serpine-type elastase) to cultured mononuclear phagocytes is associated with an increase in expression of the $\alpha_{1}$-AT gene. Subsequent studies have demonstrated that this novel regulatory loop involves interaction between exogenous neutrophil elastase and endogenous $\alpha_{1}$-AT inducing a structural rearrangement in the $\alpha_{1}$-AT molecule and exposing highly conserved conformation-specific domain of $\alpha_{1}-\mathrm{AT}$, which can then be recognized by a specific cell surface receptor, the serpinenzyme complex receptor. In the following study, we examined the effect of a bacterial metalloelastase, Pseudomonas aeruginosa elastase, on expression of $\alpha_{1}$-AT in human mononuclear phagocytes. We show that pseudomonas elastase inactivates monocyte-derived $\alpha_{1}$-AT by limited proteolysis but, in so doing, $\alpha_{1}$-AT becomes recognized by the serpin-enzyme complex receptor and mediates an increase in de novo synthesis of $\alpha_{1}-\mathrm{AT}$ in these cells. However, the concentrations of pseudomonas elastase needed to proteolytically inactivate $\alpha_{1}-\mathrm{AT}$ in monocyte culture fluid are higher than those required for inactivation of purified plasma $\alpha_{1}$-AT. Results of experiments in this report show that this can be explained, at least in part, by binding of pseudomonas elastase to another endogenous protease inhibitor, $\alpha_{2}$-macroglobulin. Thus, the results of this study further define the elaborate mechanisms by which the host mononuclear phagocyte controls the elastase- $\alpha_{1}-\mathrm{AT}$ balance and, in turn, connective tissue turnover. (Pediatr Res 29: 133-140, 1991)
\end{abstract}

Abbreviations

$\alpha_{1}$-AT, $\alpha_{1}$-antitrypsin

LPS, lipopolysaccharide

SEC, serpin-enzyme complex

Received February 22, 1990; accepted October 12, 1990

Correspondence: Dr. David Perlmutter, Department of Pediatrics, Washington University School of Medicine, 400 S. Kingshighway, St. Louis, MO 63110.

Supported in part by the Cystic Fibrosis Foundation, an American Heart Association Established Investigator Award, a Washington University/Monsanto Biomedical Research Agreement, and U.S. PHS HL 37784.
At sites of inflammation or tissue injury, an array of proteolytic enzymes is released by neutrophils, platelets, damaged tissue, activation products of the complement, coagulation, and fibrinolytic pathways as well as by invading microorganisms. These enzymes must ultimately be inactivated to prevent incidental destruction of surrounding tissue and to allow for tissue repair. Proteinase inhibitors are produced by resident mononuclear phagocytes, as well as by liver, indicating that the host has local as well as remote potential mechanisms for proteinase inactivation at sites of inflammation. One proteinase inhibitor, $\alpha_{1}$-AT, is particularly important in this regard because it inhibits a highly destructive enzyme, neutrophil elastase. Unregulated neutrophil elastase activity is probably responsible for destructive lung disease in $\alpha_{1}$-AT-deficient and -sufficient hosts and contributes to lung injury in cystic fibrosis and adult respiratory distress syndrome (1).

$\alpha_{1}$-AT is the archetype of the serine proteinase inhibitor (serpin) supergene family. It binds its target enzyme at a substratelike region within the carboxy terminal portion of the molecule. The enzyme is inactivated as a covalently stabilized enzymeinhibitor complex is formed. During complex formation, there is also structural rearrangement of the inhibitor and hydrolysis of its methionine-serine reactive-site peptide bond (2).

The net functional activity of $\alpha_{1}$-AT in complex biologic fluids may be modified by several factors. First, the reactive site methionine may be oxidized and, therein, $\alpha_{1}$-AT rendered inactive as an elastase inhibitor (3-8). Second, $\alpha_{1}$-AT may be inactivated by the limited proteolytic activity of endogenous and exogenous metallo- and thiol-enzymes (9-14). Several metallo- and thiolenzymes have been shown to cleave $\alpha_{1}$-AT at or near its reactivesite peptide bond, inactivating $\alpha_{1}$-AT without forming an enzyme-inhibitor complex. Third, the activity of $\alpha_{1}$-AT may be affected by the activity of other inhibitors present in fluids, including other serpins and inhibitors of the $\alpha_{2}$-macroglobulin class (15). $\alpha_{2}$-Macroglobulin binds proteinases of the serine, carboxyl, thiol, and metalloproteinase classes. Proteinase inactivation results from rapid receptor-mediated clearance and intracellular degradation of the $\alpha_{2}$-macroglobulin-proteinase complexes. Fourth, the concentration of $\alpha_{1}$-AT in tissue is affected by extracellular factors that regulate the synthesis of $\alpha_{1}$-AT. We now know that synthesis of $\alpha_{1}$-AT in hepatocytes is regulated by the acute phase mediator IL-6 (16). Synthesis of $\alpha_{1}$-AT in mononuclear phagocytes is regulated by IL-6 (16), bacterial LPS (17), and a novel feedback mechanism involving the neutrophil elastase- $\alpha_{1}$-AT complex as mediator $(18-20)$. In the last case, a domain in the carboxy-terminal fragment of $\alpha_{1}$-AT is newly exposed during the formation of the elastase- $\alpha_{1}$-AT complex. This domain is recognized by a cell surface receptor, SEC receptor, and a SEC receptor-linked signal transduction system for up-regulation of $\alpha_{1}$-AT gene expression (20). In the present study, we examined the effect of a prototype metalloelastase, $P$. aeru- 
ginosa elastase, on $\alpha_{1}$-AT gene expression and functional activity in a model cell culture system, primary culture of human peripheral blood monocytes. Pseudomonas elastase is capable of degrading connective tissue matrix proteins including elastin (21), collagen (22), laminin (23), serum proteins including IgG (24), C3 $(25)$, and $\alpha_{1}$-AT $(13,26)$ as well as the lymphokines interferon-gamma (27) and IL-2 (28). It has been shown to cleave $\alpha_{1}$ AT at the $\mathrm{Pro}^{357}$-Met ${ }^{358}$ bond adjacent to the reactive-site peptide bond, but the newly generated carboxy terminal fragment of $\alpha_{1^{-}}$ AT remains associated with the rest of the molecule by hydrophobic forces (26). Thus, it is possible that this prototypic metalloenzyme inactivates $\alpha_{\mathrm{r}}$-AT but, in so doing, exposes a receptor-binding domain and engages SEC receptor-mediated upregulation of $\alpha_{1}$-AT gene expression. In this study, we examined the effect of pseudomonas elastase on monocyte-derived $\alpha_{1}$-AT by SDS-PAGE, the effect of pseudomonas elastase on synthesis of $\alpha_{1}$-AT in monocytes, and the possibility that there is uptake of pseudomonas elastase by monocytes.

\section{MATERIALS AND METHODS}

Materials.Hank's balanced salt solution and Medium 199 were purchased from Microbiological Associates, Walkersville, MD, and FCS, L-glutamine, and penicillin-streptomycin were from Flow Laboratories, Inc., McLean, Va. $\left[{ }^{32} \mathrm{P}\right]$ deoxycytidine triphosphate (specific radioactivity $\sim 3000 \mathrm{Ci} / \mathrm{mmol}$ ) was obtained from New England Nuclear, Boston, MA, and $\left[{ }^{125} \mathrm{I}\right]$ sodium iodide and $\left[{ }^{14} \mathrm{C}\right]$ methylated protein standards were from Amersham Corp., Arlington Heights, IL. Other reagents included IgGSorb from Enzyme Center, Cambridge, MA, and guanidine isothiocyanate from Fluka AG, Buchs, Switzerland. Polymyxin $B$ was purchased from Boehringer Mannheim Biochemicals, Indianapolis, IN. Rabbit anti-human $\alpha_{1}$-AT and rabbit antihuman $\alpha_{2}$-macroglobulin were from Dako Corp., Santa Barbara, CA. LPS preparations extracted from Escherichia coli serotype 0111:B4 by Westphal phenolic extraction were purchased from Sigma Chemical Co., St. Louis, MO. E. coli 0113 LPS from Associates of Cape Cod, Inc., Woods Hole, MA, was also used. $P$. aeruginosa elastase was kindly supplied by Dr. Barbara Iglewski (Rochester, New York) and also purchased from Nagase and Company, Ltd., Tokyo, Japan. These preparations were homogeneous as demonstrated by SDS-PAGE and functionally active as demonstrated by digestion of Hide powder azure according to previously published methods (29). There was $<1 \mathrm{pg} /$ $\mathrm{mL}$ of LPS in these preparations as demonstrated by limulus amebocyte lysate assay (Associates of Cape Cod., Inc.). For each experiment, pseudomonas elastase was resuspended in the desired concentration in $18 \mathrm{mM}$ Tris, $\mathrm{pH} 8.0,10 \mathrm{mM} \mathrm{CaCl}_{2}, 30$ $\mathrm{mM} \mathrm{NaCl}$ buffer. Purified human plasma $\alpha_{2}$-macroglobulin was kindly supplied by Dr. L. Sottrup-Jensen (Aarhus, Denmark). Preparation of purified human plasma $\alpha_{1}$-AT and purified porcine pancreatic elastase have been previously described (18).

Cell culture. Confluent monolayers of human peripheral blood monocytes from healthy individuals were established by adherence of dextran-purified leukocytes on charged tissue culture plastic (Primaria; Becton-Dickinson Labware, Lincoln Park, NJ) (17). Each individual had a normal $\alpha_{1}$-AT allotype as defined by isoelectric focusing and plasma concentrations of $\alpha_{1}-\mathrm{AT}$.

Metabolic labeling. Confluent monolayers were rinsed and incubated at $37^{\circ} \mathrm{C}$ in the presence of methionine-free medium containing $\left[{ }^{35} \mathrm{~S}\right]$ methionine, $250 \mu \mathrm{Ci} / \mathrm{mL}$ (pulse period). To determine the net synthesis of $\alpha_{1}$-AT or control secretory proteins, cells were subjected to a short pulse interval $(20 \mathrm{~min})$ and radiolabeled proteins were detected in the cell lysate alone. To obtain radiolabeled $\alpha_{1}$-AT from cell culture fluid, cells were subjected to a long pulse interval (180 $\mathrm{min}$ ) and the cell culture fluid harvested and stored at $-70^{\circ} \mathrm{C}$. Methods for solubilization of cells and clarification of cell lysates after labeling have been described (30). Total protein synthesis was estimated by trichloroacetic acid precipitation of aliquots of cell lysates and culture fluid (31).
Immunoprecipitation and analytical gel electrophoresis. Aliquots of cell lysate or medium were incubated overnight at $4^{\circ} \mathrm{C}$ in $1 \%$ Triton $\mathrm{X}-100 / 1.0 \% \mathrm{SDS} / 0.5 \%$ deoxycholic acid, with excess antibody. Immune complexes were precipitated with excess formalin-fixed staphylococci-bearing protein A, washed, released by boiling in sample buffer, and applied to $9.0 \%$ SDSPAGE under reducing conditions (32). ${ }^{14} \mathrm{C}$-methylated molecular size markers $(200000,92500,68000,46000,30000$, and $17000 \mathrm{~mol} \mathrm{wt}$ ) were incubated on all gels. After electrophoresis, gels were stained in Coomassie brilliant blue, destained, impregnated with 2,5-diphenyloxazole (EN ${ }^{3} \mathrm{HANCE}$; New England Nuclear), and dried for fluorography on XAR X-ray film (Eastman Kodak Co., Rochester, NY). SDS-polyacrylamide gels of purified proteins or reaction mixtures were subjected to staining in Coomassie brilliant blue alone and standard unlabeled protein mixtures used as relative molecular size markers. In specific experiments, purified proteins or reaction mixtures were subjected to native gel electrophoresis according to a previously described protocol (33). Laser densitometer 2222 ultrascan XL from LKB Instruments, Inc., Houston, TX, was used for scanning of fluorograms.

Detection of RNA by RNA blot analysis. Total cellular RNA was isolated from adherent monolayers of monocytes, macrophages, or hepatoma cells by guanidine isothiocyanate extraction and ethanol precipitation (34). RNA was subjected to agaroseformaldehyde gel electrophoresis and transferred to nitrocellulose filters (35). Filters were then hybridized with ${ }^{32} \mathrm{P}$-labeled cDNA specific for human $\alpha_{1}$-AT (17).

Determination of ${ }^{125}$ I-pseudomonas elastase uptake. Pseudomonas elastase was labeled with ${ }^{125} \mathrm{I}$ using chloramine $\mathrm{T}$ and purified by gel filtration on Sephadex G10. The specific radioactivity of various preparations was $\sim 3700 \mathrm{cpm} / \mathrm{ng}$. For uptake studies, separate monolayers of monocytes were washed with PBS and incubated at $37^{\circ} \mathrm{C}$ for specified time intervals with ${ }^{125} \mathrm{I}-$ pseudomonas elastase in Medium 199 containing $10 \mathrm{mM} \mathrm{N-2-}$ hydroxyethylpiperazine- $N^{\prime}$-2-ethanesulfonic acid and $0.1 \mathrm{mg} /$ $\mathrm{mL}$ cytochrome $\mathrm{C}$. The cells were then rinsed in PBS at $4^{\circ} \mathrm{C}$ and cell-associated radioactivity determined in $1 \mathrm{~N} \mathrm{NaOH}$ homogenates. Specific uptake was defined as the difference between total and nonspecific uptake. Nonspecific uptake was determined by the addition of 200 -fold molar excess of unlabeled pseudomonas elastase during the uptake experiments.

\section{RESULTS}

Pseudomonas elastase cleaves monocyte-derived $\alpha_{1}-A T$. To determine the effect of pseudomonas elastase on monocytederived $\alpha_{1}$-AT, we first examined its effect on purified human plasma $\alpha_{1}$-AT. Reaction mixtures of $\alpha_{1}$-AT and pseudomonas elastase or porcine pancreatic elastase were subjected to SDSPAGE after incubation at $37^{\circ} \mathrm{C}$ for $60 \mathrm{~min}$ (Fig. 1 a). Pseudomonas elastase cleaves $\alpha_{1}$-AT in concentration-dependent fashion. The effect is first evident at a pseudomonas elastase concentration of $10 \mathrm{ng} / \mathrm{mL}$ in Figure $1 a$ but is observed at a concentration of $100 \mathrm{pg} / \mathrm{mL}$ in other experiments (data not shown). There is a step-wise cleavage with at least two intermediate cleavage products before reaching the well-characterized $\sim 51-\mathrm{kD}$ modified form of $\alpha_{1}$-AT as a result of the action of pseudomonas elastase at $10 \mu \mathrm{g} / \mathrm{mL}$. This form of $\alpha_{1}-\mathrm{AT}$ comigrated with the $51-\mathrm{kD}$ form of $\alpha_{1}$-AT in the reaction mixture containing $\alpha_{1}$-AT and serine-type pancreatic elastase (Fig. 1a, last lane).

Monocyte-derived $\alpha_{1}$-AT was reacted with pseudomonas elastase and pancreatic elastase in the same concentrations. Separate monolayers of monocytes were labeled with ${ }^{35} \mathrm{~S}$-methionine for $180 \mathrm{~min}$. The resulting cell culture fluid, containing newly synthesized and radiolabeled $\alpha_{1}-\mathrm{AT}$ as well as other secretory proteins, was harvested, clarified, and incubated for $60 \mathrm{~min}$ at $37^{\circ} \mathrm{C}$ with pseudomonas elastase or pancreatic elastase. The reaction mixture was then subjected to immunoprecipitation with antihuman $\alpha_{1}$-AT, followed by SDS-PAGE and fluorography (Fig. $1 b$ ). There are several forms of $\alpha_{1}$-AT in the cell culture fluid of 
a

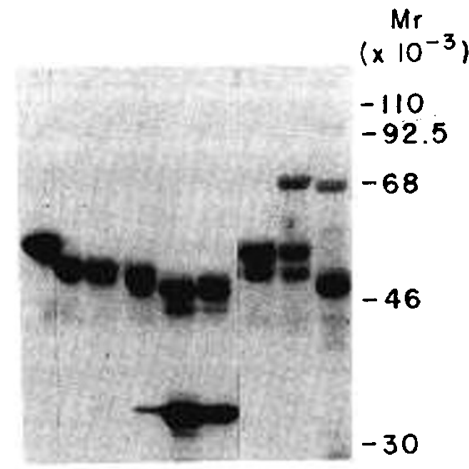

Ps elas $(\mu \mathrm{g} / \mathrm{ml}) 0.01 .1 \quad 1 \quad 101000000$ Panc elos $(\mu \mathrm{g} / \mathrm{ml}) 0000000110100$ b

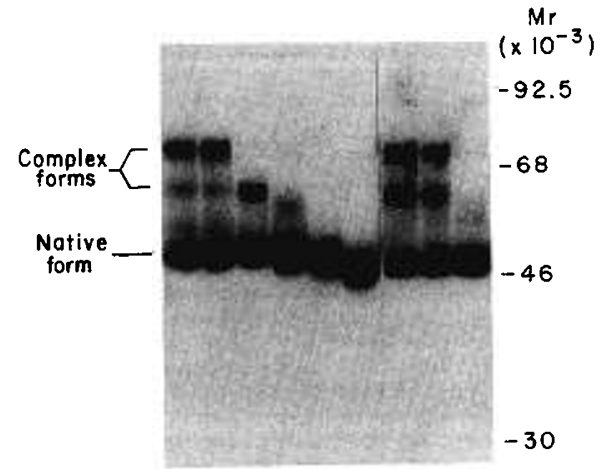

Ps elas $(\mu \mathrm{g} / \mathrm{ml}) 0.01 \quad 1.1 \quad 1 \quad 10 \quad 1000000$

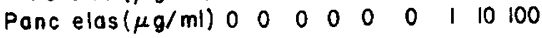

Fig. 1. Cleavage of $\alpha_{1}$-AT by pseudomonas elastase. Purified human plasma $\alpha_{1}-\mathrm{AT}(10 \mu \mathrm{g} / \mathrm{mL})(a)$ or monocyte-derived $\alpha_{1}-\mathrm{AT}(b)$ was reacted with pseudomonas elastase or pancreatic elastase in the specified concentrations. Reaction mixtures were subjected to SDS-PAGE and unlabeled polypeptides demonstrated by Coomassie blue staining $(a)$ or to immunoprecipitation with anti- $\alpha_{1}-\mathrm{AT}$ followed by SDS-PAGE and radiolabeled polypeptides demonstrated by fluorography $(b)$. Molecular mass markers are indicated at the right margin. The results were representative of three separate experiments in each case.

monocytes (first lane of Fig. $1 b$; also ref. 36) including the 55$\mathrm{kD}$ native protein and 66- and 75-kD forms of $\alpha_{1}$-AT in complex with endogenous elastase. Pseudomonas elastase cleaves native $55-\mathrm{kD} \alpha_{1}-\mathrm{AT}$ to a $51-\mathrm{kD}$ polypeptide. The cleavage is first apparent at pseudomonas elastase concentrations between 0.1 and $1.0 \mu \mathrm{g} / \mathrm{mL}$. Thus, a much higher concentration of pseudomonas elastase is required to cleave monocyte-derived $\alpha_{1}$-AT (lowest effective concentration $0.1-1.0 \mu \mathrm{g} / \mathrm{mL}$ ) than to cleave purified plasma $\alpha_{1}$-AT (lowest effective concentration $0.1-1.0 \mathrm{ng} / \mathrm{mL}$ ). This difference could not be attributed to the salt concentration in the reaction mixture; i.e. there was no difference when the $\mathrm{NaCl}$ concentration of the reaction buffer was reduced from 110 to $55 \mathrm{mM}$ (data not shown). Furthermore, this difference could not be attributed to the presence of complex as well as native forms of $\alpha_{1}$-AT in monocyte culture fluid as compared to the presence of only the native form of $\alpha_{1}$-AT in purified plasma $\alpha_{1}$ AT preparations-there was no difference in the concentration of pseudomonas elastase required to cleave purified plasma $\alpha_{1-}$ AT alone as compared to purified plasma $\alpha_{1}$-AT after it had been reacted with purified human neutrophil elastase under conditions that resulted in steady-state concentrations of native and complex form of $\alpha_{1}$-AT (data not shown). Thus, it is much more likely that the difference in effective concentrations of pseudomonas elastase on $\alpha_{1}-\mathrm{AT}$ in monocyte culture fluid is related to another constituent of that culture fluid, such as $\alpha_{2}$ macroglobulin (see below).

Results shown in Figure $1 b$ also indicate that there is step-wise cleavage with at least two intermediate cleavage products. The final cleavage product comigrates with the modified form of $\alpha_{1}$ -
$\mathrm{AT}$ as demonstrated in the last lane. In this case, there has been dissociation of the endogenous $\alpha_{1}$-AT-elastase complex leaving only modified $\alpha_{1}$-AT by generating a vast excess of serine elastase with exogenous pancreatic elastase. The progressive disappearance of the 66- and $75-\mathrm{kD} \alpha_{1}$-AT-elastase complexes during incubation with increasing concentrations of pseudomonas elastase or pancreatic elastase is also probably attributable to the progressive functional inactivation of $\alpha_{1}$-AT.

Pseudomonas elastase mediates an increase in net synthesis of $\alpha_{1}-A T$ by monocytes. Separate monolayers of monocytes were incubated for $4 \mathrm{~h}$ at $37^{\circ} \mathrm{C}$ with serum-free control medium, medium supplemented with pseudomonas elastase in a concentration that cleaves monocyte-derived $\alpha_{1}$-AT (100 ng/mL; Fig. $1 b)$, or medium supplemented with pancreatic elastase in a concentration previously shown to be effective in mediating upregulation of $\alpha_{1}-\mathrm{AT}$ synthesis $(50 \mathrm{ng} / \mathrm{mL}$; refs. 18 and 19). Monocytes were then rinsed and subjected to metabolic labeling and newly synthesized, radiolabeled $\alpha_{1}$-AT in cell lysates was demonstrated by immunoprecipitation, SDS-PAGE followed by fluorography (Fig. 2). Pseudomonas elastase mediates an increase in synthesis of $\alpha_{1}$-AT. In this experiment, the effect of pseudomonas elastase was compared to the effect of serine-type pancreatic elastase. However, the effect of pancreatic elastase is submaximal, inasmuch as its full effect requires $18-24 \mathrm{~h}(18,19)$. When compared to pancreatic elastase or neutrophil elastase at optimal conditions, the magnitude of the effect of pseudomonas elastase and the serine elastases is similar (data not shown). The effect is specific in that other proteins, such as complement protein factor $\mathrm{B}$, are not affected in the same experiment (Fig. 2, right panel). The effect of pseudomonas elastase is also concentration-dependent (Fig. 3). The lowest effective concentration for mediating the regulatory effect, $100 \mathrm{ng} / \mathrm{mL}$, correlates with the lowest effective concentration for limited proteolysis of monocyte-derived $\alpha_{1}$ AT. The effect of pseudomonas elastase on synthesis of $\alpha_{1}$-AT reaches a plateau at $250-500 \mathrm{ng} / \mathrm{mL}$.

The effect of pseudomonas elastase on synthesis of $\alpha_{1}$-AT is also time-dependent. It is first evident after a 4-h incubation and is maximal after $8 \mathrm{~h}$. The effect wanes by $8-16 \mathrm{~h}$ (data not shown).

Pseudomonas elastase also mediates an increase in steady-state levels of $\alpha_{1}$-AT mRNA (Fig. 4). Monocytes were incubated for 4 $h$ in serum-free control medium or medium supplemented with

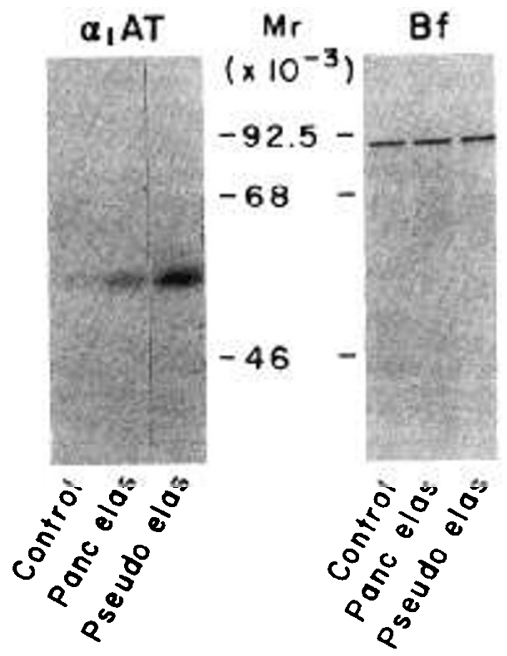

Fig. 2. Effect of pseudomonas elastase on synthesis of $\alpha_{1}$-AT in human monocytes. Monocytes were incubated for $4 \mathrm{~h}$ in serum-free control medium, medium supplemented with pancreatic elastase $(50 \mathrm{ng} /$ $\mathrm{mL}$ ) or medium supplemented with pseudomonas elastase $(500 \mathrm{ng} / \mathrm{mL})$. Synthesis of $\alpha_{1}-\mathrm{A} \Upsilon$ and complement protein factor $\mathrm{B}(B f)$ was determined by methods described in Materials and Methods. Molecular mass markers are indicated at the right margin. The results were representative of three separate experiments. 


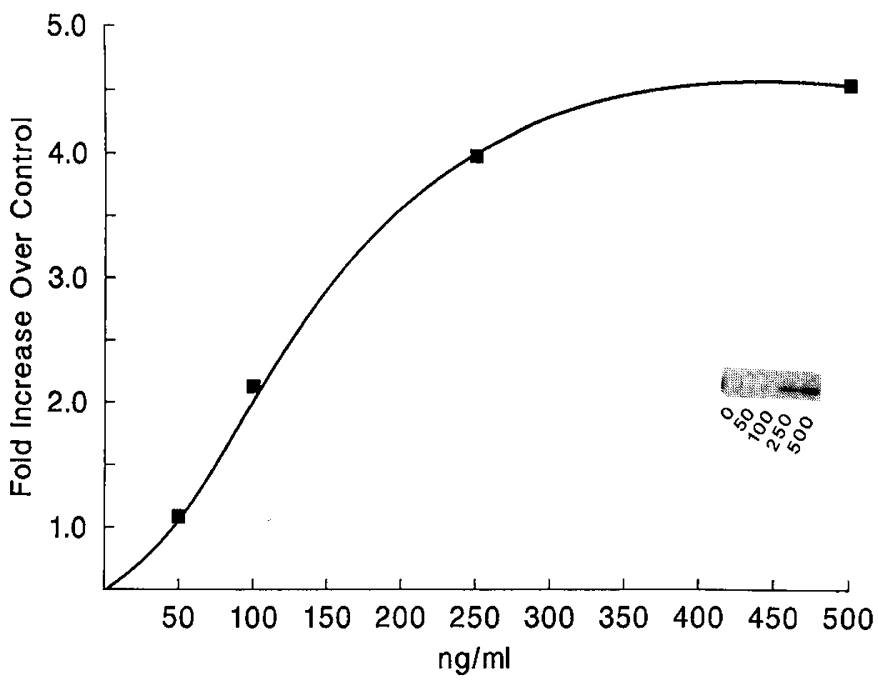

Fig. 3. Effect of pseudomonas elastase on synthesis of $\alpha_{1}$-AT is concentration-dependent. Monocytes were incubated for $4 \mathrm{~h}$ in serum-free control medium or medium supplemented with pseudomonas elastase in the specified concentrations. Synthesis of $\alpha_{1}$-AT was determined by methods described in Materials and Methods. A fluorogram is shown in the inset. The results of densitometric scanning of this fluorogram is shown in the graph. The results were representative of two separate experiments.

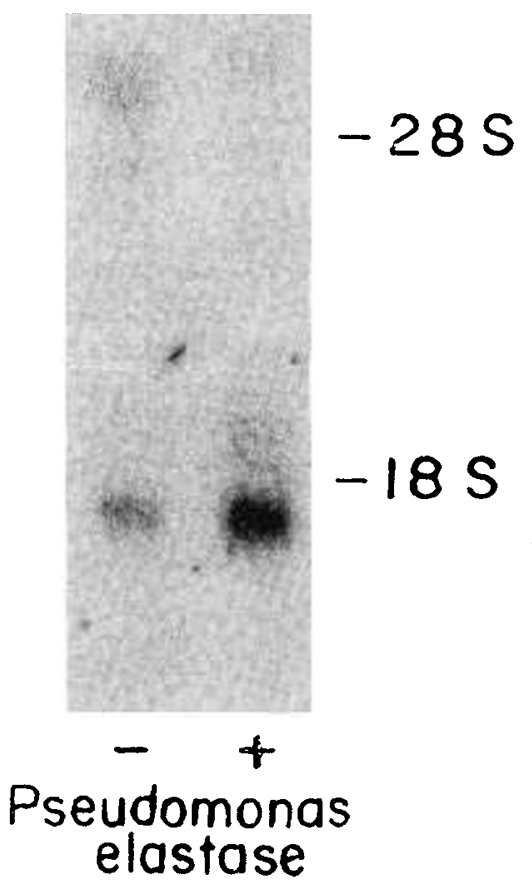

Fig. 4. Effect of pseudomonas elastase on steady-state levels of $\alpha_{1}$-AT mRNA. Monocytes were incubated for $4 \mathrm{~h}$ in serum-free control medium or medium supplemented with pseudomonas elastase at $250 \mathrm{ng} / \mathrm{mL}$. Total cellular RNA was then isolated and subjected to RNA blot analysis as described in Materials and Methods. Equal amounts of RNA were loaded in each lane. There was no difference in the intensity of ethidiumbromide stained ribosomal RNA (data not shown). Twenty-eight-S and $18 \mathrm{~S}$ ribosomal RNA markers are indicated at the right margin. The results were representative of two separate experiments.

pseudomonas elastase in a concentration of $250 \mathrm{ng} / \mathrm{mL}$. Total cellular RNA was then isolated, purified, and subjected to RNA blot analysis. There is a significant increase in $\alpha_{1}$-AT mRNA levels in the presence of pseudomonas elastase. The magnitude of the effect is similar to that of neutrophil elastase $(18,19)$.
We next examined the possibility that the effect of pseudomonas elastase on $\alpha_{1}$-AT synthesis is similar to that of neutrophil elastase in terms of cell-surface recognition and signal transduction (Fig. 5). In this case, we examined the effect on monocyte $\alpha_{1}$-AT synthesis of pseudomonas elastase in the absence or presence of antiserum to the receptor binding domain of $\alpha_{1}-\mathrm{AT}$. The antiserum was raised in rabbits by immunization of a keyhole limpet hemocyanin-conjugated synthetic peptide (peptide 105Y) corresponding to the ligand binding domain of $\alpha_{1}$ AT (20). It recognizes $\alpha_{1}$-AT-elastase or $\alpha_{1}$-AT-trypsin complexes by ELISA and immunoprecipitation, blocks binding and uptake of $\alpha_{1}$-AT-neutrophil elastase and $\alpha_{1}$-AT-trypsin complexes, and blocks the effect of neutrophil elastase and $\alpha_{1}$-AT-neutrophil elastase complexes on synthesis of $\alpha_{1}$-AT in monocytes (Joslin G, Fallon RJ, Perlmutter DH, unpublished observations).

For the experiment shown in Figure 5, monocytes were incubated for $4 \mathrm{~h}$ in control serum-free medium or medium supplemented with pseudomonas elastase in suboptimal concentrations alone or together with several antisera or antibodies. Monocytes were then rinsed and subjected to metabolic labeling and newly synthesized radiolabeled $\alpha_{1}$-AT was detected in the same analytical system as described above. The increase in synthesis mediated by pseudomonas elastase was blocked by antiserum to receptor-binding domain of $\alpha_{1}$-AT but not by preimmune rabbit serum or by an antibody to the receptor-binding domain of $\alpha_{2-}$ macroglobulin. These data suggest that a receptor-binding domain on endogenous $\alpha_{1}$-AT molecules is exposed by the distinct

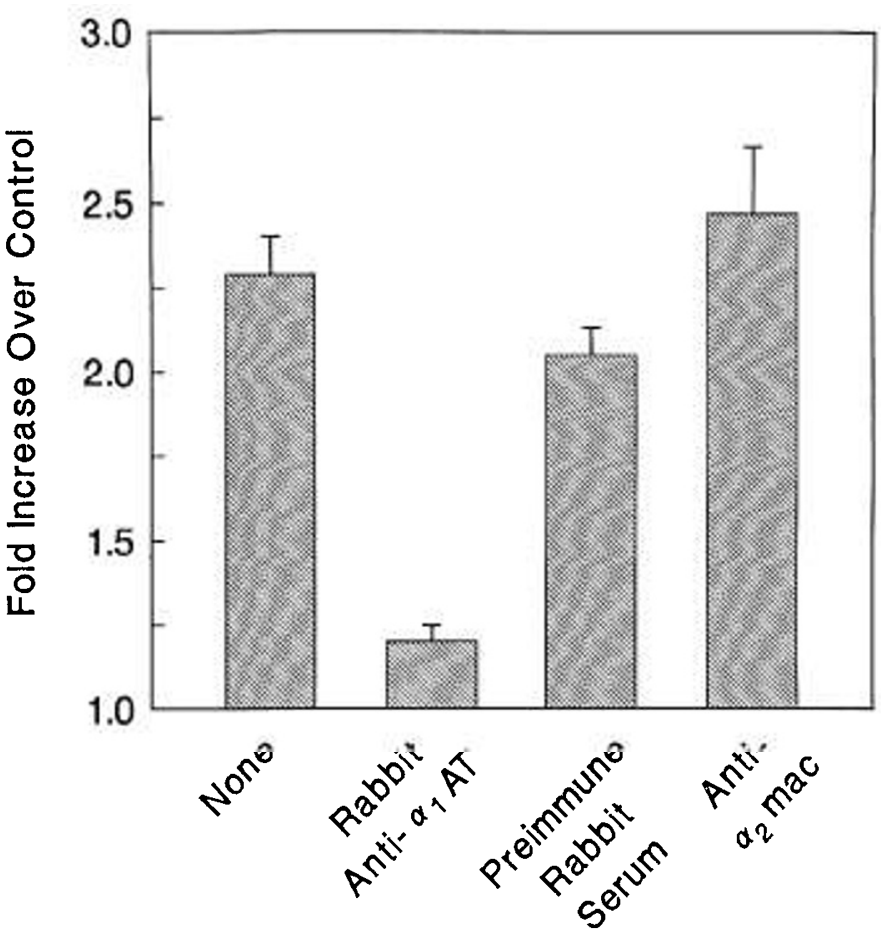

Fig. 5. Antibody to the receptor-binding domain of $\alpha_{1}$-AT blocks the effect of pseudomonas elastase on synthesis of $\alpha_{1}$-AT. Monocytes were incubated for $4 \mathrm{~h}$ at $37^{\circ} \mathrm{C}$ in serum-free control medium, medium supplemented with pseudomonas elastase in suboptimal concentrations $(100 \mathrm{ng} / \mathrm{mL})$, medium supplemented with pseudomonas elastase together with a MAb to the receptor-binding domain of $\alpha_{2}$-macroglobulin (F2B2, $0.6 \mu \mathrm{g} / \mathrm{mL}$ final concentration), rabbit antiserum to the receptor binding domain of $\alpha_{1}$-AT (rabbit anti-keyhole limpet hemocyanin conjugated peptide $105 \mathrm{Y}, 1.2 \mu \mathrm{g} / \mathrm{mL}$ final concentration, or preimmune rabbit serum $\left(1.2 \mu \mathrm{g} / \mathrm{mL}\right.$ final concentration). Synthesis of $\alpha_{1}$-AT was examined as described above and results are shown as fold increase over control on the basis of densitometric scanning of fluorograms. The mean \pm 1 $\mathrm{SD}$ from three separate experiments is shown. Antibody, antiserum, or serum used in this experiment had no independent effect on synthesis of $\alpha_{1}$-AT (data not shown). 
enzymatic action of exogenous pseudomonas elastase and is recognized by the SEC receptor to mediate up-regulation of $\alpha_{1}$ AT gene expression.

Uptake of pseudomonas elastase by monocytes. To determine the fate of pseudomonas elastase, we incubated monocytes with radioiodinated pseudomonas elastase at $37^{\circ} \mathrm{C}$ for time intervals up to $4 \mathrm{~h}$. Duplicate monolayers were incubated with $\mathrm{I}^{125}$ pseudomonas elastase in the presence of 200-fold molar excess of unlabeled pseudomonas elastase. Cell monolayers were then rinsed vigorously and cell-associated radioactivity measured (Fig. $6 a$ ). The results indicate that there is specific, time-dependent uptake of pseudomonas elastase. There is a relatively rapid increase in cell-associated radioactivity. Rate of accumulation within the cells decreases by 30-60 min (Fig. $6 a$ ) and reaches a plateau by $8-16 \mathrm{~h}$ (data not shown).

We next examined the possibility that uptake of ${ }^{125}$ I-pseudomonas elastase in these experiments represents uptake of pseudomonas elastase- $\alpha_{2}$-macroglobulin complexes. Human monocytes synthesize and secrete $\alpha_{2}$-macroglobulin (37). Monocytes also express $\alpha_{2}$-macroglobulin-proteinase receptors that are capable of uptake and endocytosis of $\alpha_{2}$-macroglobulin-pseudomonas elastase complexes (15). Monocytes were incubated with ${ }^{125} \mathrm{I}-$ pseudomonas elastase at $37^{\circ} \mathrm{C}$ for $1 \mathrm{~h}$ in the absence or presence of 100-fold molar excess unlabeled pseudomonas elastase, antibody to the receptor-binding domain of $\alpha_{2}$-macroglobulin (kindly provided by Dr. F. van Leuven, Leuven, Belgium and described in ref. 38), or antiserum to the receptor-binding domain of $\alpha_{1}$-AT as described above (Fig. $6 b$ ). After $2 \mathrm{~h}$, the cells were washed and lysed and cell-associated radioactivity determined. The results indicate that uptake of pseudomonas elastase is blocked by antibody to the receptor-binding domain of $\alpha_{2^{-}}$ macroglobulin but not by antibody to the ligand-binding domain of $\alpha_{1}$-AT. Uptake of pseudomonas elastase is therefore mediated, at least in part, by the $\alpha_{2}$-macroglobulin-proteinase receptor.

To further establish that uptake of pseudomonas elastase by monocytes represents uptake of pseudomonas elastase- $\alpha_{2}$-macroglobulin complexes, we examined the possibility that pseudomonas elastase binds to and induces the conformational change of $\alpha_{2}$-macroglobulin to the "fast" form, which is recognized by the $\alpha_{2}$-macroglobulin-proteinase receptor $(38,39)$. First, we demonstrated that pseudomonas elastase mediated a concentrationdependent conversion of purified human plasma $\alpha_{2}$-macroglobulin to its "fast" conformation in native PAGE (Fig. 7a). Second,

A.

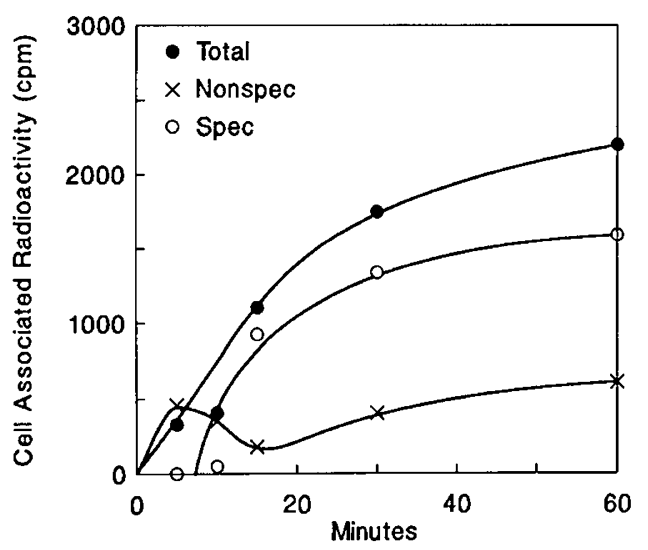

we demonstrated that ${ }^{125} \mathrm{I}$-pseudomonas elastase associated with unlabeled $\alpha_{2}$-macroglobulin by autoradiography of the same native polyacrylamide gel (Fig. 7a). Third, we showed that the interaction between unlabeled pseudomonas elastase and $\alpha_{2}$ macroglobulin resulted in similar cleavage products as that between unlabeled trypsin and $\alpha_{2}$-macroglobulin as shown by SDSPAGE (Fig. $7 b$ ). Finally, we showed that ${ }^{125}$ I-pseudomonas elastase was associated with endogenous $\alpha_{2}$-macroglobulin after incubation with monocytes at $37^{\circ} \mathrm{C}$ for $4 \mathrm{~h}$ (Fig. 8). For this experiment, cell culture fluid was harvested and cells lysed after the incubation and the resulting samples subjected to immunoprecipitation with antibody to $\alpha_{2}$-macroglobulin followed by SDS-PAGE under reducing conditions and finally autoradiography (Fig. 6, left panel). The results indicate the presence of an $\sim 32$-kD radiolabeled polypeptide corresponding to pseudomonas elastase and $\sim 90-$ and $\sim 120-\mathrm{kD}$ radiolabeled polypeptides. The 90-kD polypeptide corresponds to the monomeric form of $\alpha_{2}$-macroglobulin-pseudomonas elastase complexes. The $120-\mathrm{kD}$ polypeptide corresponds to heat-induced fragmentation of the internal thiolester of $\alpha_{2}$-macroglobulin dimers in complex with pseudomonas elastase (as shown in similar studies with bacterial and neutrophil proteinases in refs. 33 and 40 ). Radiolabeled $\sim 32-$ $\mathrm{kD}, \sim 90-\mathrm{kD}$, and $\sim 120-\mathrm{kD}$ polypeptides are also immunoprecipitated from cell lysates by anti- $\alpha_{2}$-macroglobulin (data not shown). Moreover, using these samples, a radiolabeled polypeptide corresponding to "fast" $\alpha_{2}$-macroglobulin is demonstrated in autoradiography of native PAGE (data not shown). The formation of a complex with $\alpha_{2}$-macroglobulin is specific as shown by immunoprecipitation of an aliquot of the same cell culture fluid with antibody to $\alpha_{1}$-AT (Fig. 8, right panel). In this case, there is only an $\sim 32-\mathrm{kD}$ polypeptide corresponding to the radiolabeled pseudomonas elastase used as ligand in the experiment. These results suggest that ${ }^{125}$ I-pseudomonas elastase binds to endogenous monocyte $\alpha_{2}$-macroglobulin and that uptake of elastase is mediated by the $\alpha_{2}$-macroglobulin-proteinase receptor. These results also suggest that the higher concentrations of pseudomonas elastase necessary for cleavage of $\alpha_{1}$-AT in monocyte culture fluid as compared with purified plasma $\alpha_{1}-\mathrm{AT}$ are, at least in part, due to binding of that elastase by endogenous $\alpha_{2}-$ macroglobulin and uptake of the resulting complex by $\alpha_{2}$-macroglobulin-proteinase receptor-mediated endocytosis.

\section{DISCUSSION}

The results of these experiments suggest that mononuclear phagocytes, cells that are widely distributed and even reside

B.

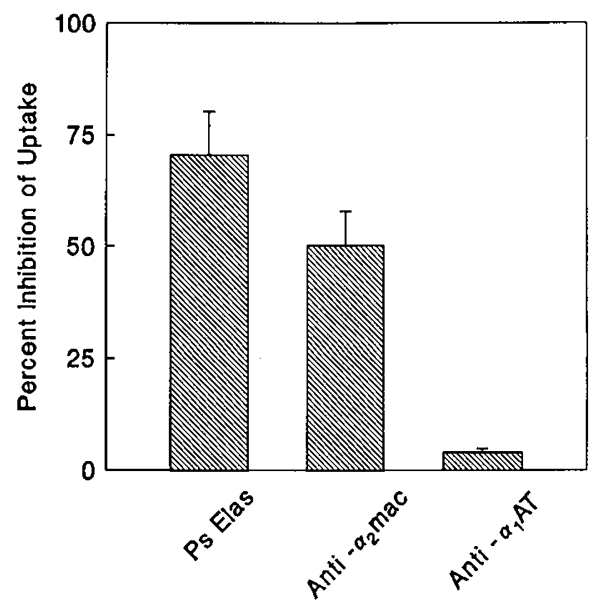

Fig. 6. Uptake of pseudomonas elastase by monocytes. $A$, monocytes were incubated at $37^{\circ} \mathrm{C}$ with ${ }^{125} \mathrm{I}$-pseudomonas elastase $(500 \mathrm{ng} / \mathrm{mL}) \mathrm{in}$ the absence (total binding) or presence (nonspecific binding) of 200 -fold molar excess unlabeled pseudomonas elastase for the specified time intervals. Cells were then rinsed in PBS and lysed in $1 \mathrm{~N} \mathrm{NaOH}$ and cell-associated radioactivity was measured. Specific binding represents the difference between total and nonspecific binding. $B$, monocytes were incubated at $37^{\circ} \mathrm{C}$ with ${ }^{125} \mathrm{I}$-pseudomonas elastase $(500 \mathrm{ng} / \mathrm{mL})$ in the absence or presence of unlabeled pseudomonas elastase $(100 \mu \mathrm{g} / \mathrm{mL})$, antiserum to the receptor-binding domain of $\alpha_{1}$-AT $(1.2 \mu \mathrm{g} / \mathrm{mL})$, or antibody to the receptor binding domain of $\alpha_{2}$-macroglobulin $(0.6 \mu \mathrm{g} / \mathrm{mL})$. Cell associated radioactivity was measured and results expressed as percent inhibition of uptake. 

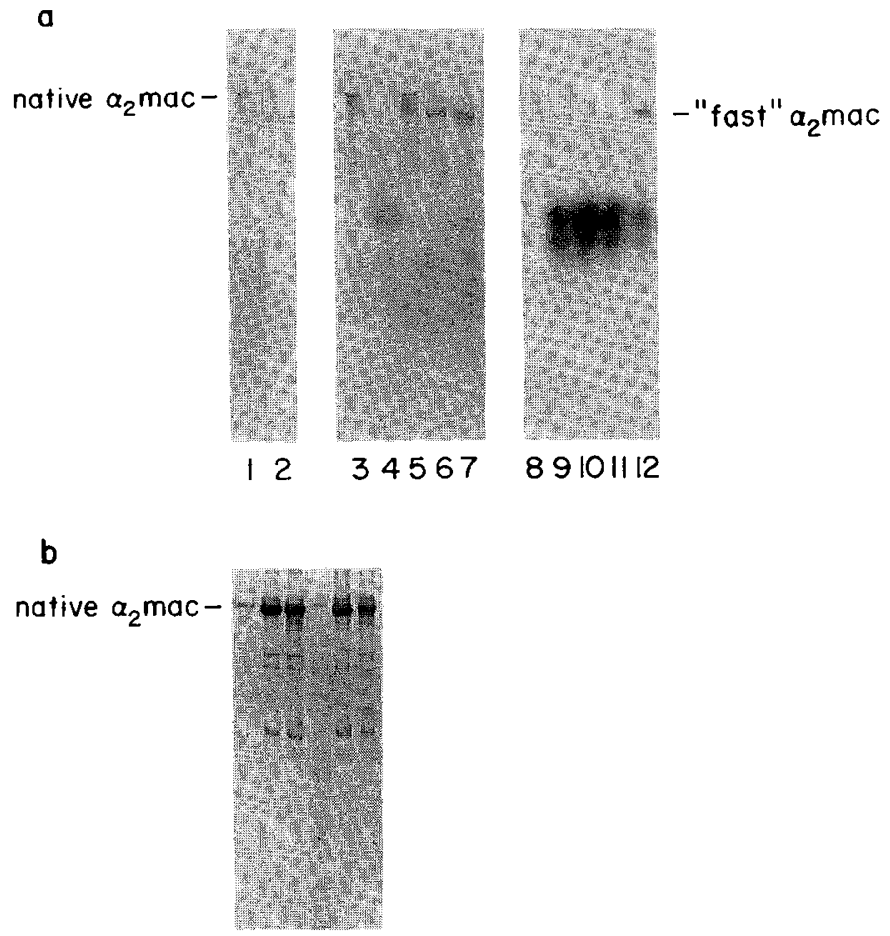

123456

Fig. 7. Interaction between pseudomonas elastase and $\alpha_{2}$-macroglobulin. Unlabeled pseudomonas elastase, ${ }^{125}$ I-pseudomonas elastase or unlabeled bovine pancreatic N-tosyl-L-phenylalanyl-chloromethyl ketonetreated trypsin was reacted with purified human $\alpha_{2}$-macroglobulin at $37^{\circ} \mathrm{C}$ for $60 \mathrm{~min}$ in $18 \mathrm{mM}$ Tris, $\mathrm{pH} 8.0 / 10 \mathrm{mM} \mathrm{CaCl} / 30 \mathrm{mM} \mathrm{NaCl}$ buffer for pseudomonas elastase or $10 \mathrm{mM} \mathrm{Na}$ phosphate ( $\mathrm{pH}$ 7.0) buffer for trypsin. Reactions were terminated with $100 \mathrm{mM}$ EDTA or $2 \mathrm{mM}$ phenylmethyl sulfonyl fluoride. Reaction mixtures were then subjected to native PAGE $(A)$ or SDS-PAGE $(B)$. Gels were then subjected to Coomassie blue staining ( $a$, lanes $1-7$ and $b$ ) or autoradiography $(A$, lanes 8-12). The migration of native ("slow") $\alpha_{2}$-macroglobulin ( $\alpha_{2}$-mac) and that of "fast" $\alpha_{2}$-mac are indicated in the left and right margins, respectively. a: Lane 1, $\alpha_{2}$-mac $(1 \mu \mathrm{g} / \mathrm{mL})$; lane $2, \alpha_{2}$-mac $(1 \mu \mathrm{g} / \mathrm{mL})+$ trypsin $(1 \mu \mathrm{g} / \mathrm{mL}) ;$ lane $3, \alpha_{2}$-mac $(1 \mu \mathrm{g} / \mathrm{mL})$; lane 4 , pseudomonas elastase (Ps elas) $(1 \mu \mathrm{g} / \mathrm{mL}) ;$ lane $5, \alpha_{2}$-mac $(1 \mu \mathrm{g} / \mathrm{mL})+$ Ps elas $(0.01$ $\mu \mathrm{g} / \mathrm{mL}) ;$ lane 6, $\alpha_{2}-\mathrm{mac}(1 \mu \mathrm{g} / \mathrm{mL})+$ Ps elas $(0.1 \mu \mathrm{g} / \mathrm{mL}) ;$ lane $7, \alpha_{2}$-mac $(1 \mu \mathrm{g} / \mathrm{mL})+$ Ps elas $(1 \mu \mathrm{g} / \mathrm{mL}) ;$ lane $8, \alpha_{2}$-mac $(1 \mu \mathrm{g} / \mathrm{mL})$; lane $9,{ }^{125} \mathrm{I}-$ Ps elas $(0.2 \mu \mathrm{g} / \mathrm{mL})$; lane $10, \alpha_{2}$-mac $(1 \mu \mathrm{g} / \mathrm{mL})+{ }^{125} \mathrm{I}$-Ps elas $(0.0004$ $\mu \mathrm{g} / \mathrm{mL})$; lane $11, \alpha_{2}-\mathrm{mac}(1 \mu \mathrm{g} / \mathrm{mL})+{ }^{125} \mathrm{I}-\mathrm{Ps}$ elas $(0.004 \mu \mathrm{g} / \mathrm{mL}) ;$ lane $12, \alpha_{2}$-mac $(1 \mu \mathrm{g} / \mathrm{mL})+{ }^{125} \mathrm{I}-\mathrm{Ps}$ elas $(0.04 \mu \mathrm{g} / \mathrm{mL}) . b$ : Lane $1, \alpha_{2}$-mac $(1$ $\mu \mathrm{g} / \mathrm{mL})$; lane 2, $\alpha_{2}$-mac $(1 \mu \mathrm{g} / \mathrm{mL})+$ Ps elas $(0.01 \mu \mathrm{g} / \mathrm{mL}) ;$ lane 3, $\alpha_{2}-$ $\operatorname{mac}(1 \mu \mathrm{g} / \mathrm{mL})+$ Ps elas $(0.1 \mu \mathrm{g} / \mathrm{mL}) ;$ lane $4, \alpha_{2}$ - $\mathrm{mac}(1 \mu \mathrm{g} / \mathrm{mL}) ;$ lane 5 , $\alpha_{2}-\mathrm{mac}(1 \mu \mathrm{g} / \mathrm{mL})+\operatorname{trypsin}(0.01 \mu \mathrm{g} / \mathrm{mL}) ;$ lane $6, \alpha_{2}-\mathrm{mac}(1 \mu \mathrm{g} / \mathrm{mL})+$ trypsin $(0.1 \mu \mathrm{g} / \mathrm{mL})$.

within epithelial linings, are endowed with a complex repertoire of responses for controlling proteolytic activity at sites of tissue injury. Mononuclear phagocytes secrete a number of protease inhibitors including $\alpha_{1}$-AT and $\alpha_{2}$-macroglobulin. We show here that mononuclear phagocytes possess a signal transduction pathway for increasing the synthesis of $\alpha_{1}$-AT when extracellular $\alpha_{1}$ AT is cleaved and inactivated by the action of a prototype metalloenzyme, pseudomonas elastase. It was of some interest to us that higher concentrations of pseudomonas elastase were necessary to cleave $\alpha_{1}$-AT in the culture fluid of monocytes as compared with purified plasma $\alpha_{1}-\mathrm{AT}$. This does not necessarily mean that the $\alpha_{1}$-AT molecule in monocyte culture fluid is structurally or functionally different than that present in plasma. We reasoned that it was much more likely that another product of the monocyte was involved and showed that the difference in concentrations of pseudomonas elastase necessary for cleavage of $\alpha_{1}$-AT in monocyte culture fluid as compared with purified

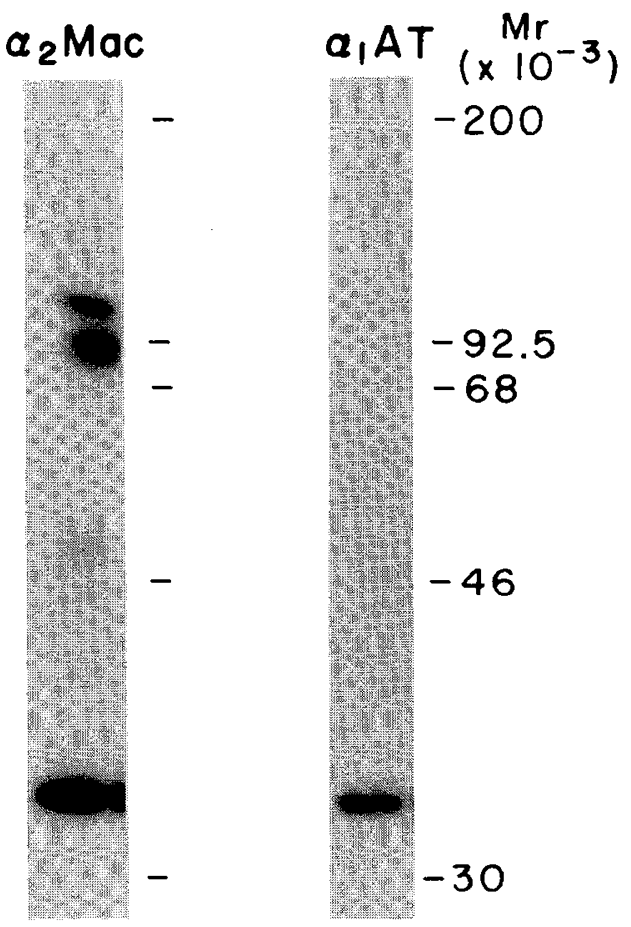

Fig. 8. Fate of radioiodinated pseudomonas elastase in monocyte cultures. Monocytes were incubated for $4 \mathrm{~h}$ at $37^{\circ} \mathrm{C}$ with ${ }^{125} \mathrm{I}$-pseudomonas elastase $(500 \mathrm{ng} / \mathrm{mL})$. Cell culture fluid was harvested and subjected to immunoprecipitation followed by SDS-PAGE and then fluorography. Immunoprecipitation with anti- $\alpha_{2}$-macroglobulin is shown in the left panel and with anti $\alpha_{1}$-AT in the right panel. Molecular mass markers are indicated at the right margin.

plasma $\alpha_{1}$-AT could be in part related to binding of pseudomonas elastase to monocyte-derived $\alpha_{2}$-macroglobulin. We also showed that the mononuclear phagocytes possess the capacity for receptor-mediated uptake and degradation of endogenous $\alpha_{2}$-macroglobulin-exogenous pseudomonas elastase complexes.

The mechanism by which neutrophil elastase- $\alpha_{1}$-AT and proteolytic inactivated $\alpha_{1}$-AT regulate mononuclear phagocyte $\alpha_{1}$ AT gene expression has been the subject of detailed investigation $(18-20)$. We have recently shown that a region within the carboxy terminal fragment of $\alpha_{1}$-AT is recognized by an abundant highaffinity receptor, SEC receptor, on the plasma membrane of human hepatoma-derived hepatocytes and human mononuclear phagocytes (20). This receptor-binding domain is not exposed in native $\alpha_{1}-\mathrm{AT}$, but becomes available for cell-surface binding when $\alpha_{1}$-AT undergoes structural rearrangement during complex formation or during proteolytic inactivation. Because the specificity of this ligand receptor interaction is similar to the specificity of in vivo $\alpha_{1}$-AT-proteinase complex clearance (41), and because there is endocytosis and lysosomal degradation of $\alpha_{1}$-AT-protease complexes mediated by the SEC receptor in vitro (42), it is likely that the SEC receptor is responsible for clearance of $\alpha_{1}$-ATelastase complexes as well as for activating the signal transduction pathway for increasing $\alpha_{1}$-AT gene expression.

Several results in our report indicate that a similar mechanism is responsible for the regulatory effect of pseudomonas elastase on $\alpha_{1}$-AT gene expression-i.e. that pseudomonas elastase induces structural rearrangement of endogenous $\alpha_{1}$-AT during proteolytic inactivation, thereby exposing a domain for recognition by the SEC receptor. First, there is a strong correlation between the concentrations necessary for proteolytic inactivation of $\alpha_{1}$-AT and those necessary for increasing synthesis of $\alpha_{1}$-AT. Second, there is a correlation between the time frame within which pseudomonas elastase affects $\alpha_{1}$-AT synthesis and the time frame for uptake and removal of pseudomonas elastase from its putative substrate. Third, a pretranslational mechanism is re- 
sponsible for the effect of pseudomonas elastase on $\alpha_{1}$-AT gene expression as well as for signals transduced by the SEC receptor $(18-20)$. Finally, the regulatory effect of pseudomonas elastase on $\alpha_{1}$-AT synthesis is specifically blocked by antibody to the domain of $\alpha_{1}$-AT that is recognized by the SEC receptor.

Further studies will be necessary to more completely understand the interaction between pseudomonas elastase or other metalloproteinases and endogenous $\alpha_{2}$-macroglobulin. $\alpha_{2}$-Macroglobulin does not completely inactivate its proteinase ligands. In fact, some enzymes have enhanced activity when bound to $\alpha_{2}$-macroglobulin (43). Nevertheless, the net physiologic activity of enzymes bound to $\alpha_{2}$-macroglobulin is probably negligible, inasmuch as there is rapid receptor-mediated clearance and intracellular degradation of $\alpha_{2}$-macroglobulin-protease complexes in many cell types including mononuclear phagocytes, fibroblasts, syncytiotrophoblasts, and hepatocytes (15). We show here that pseudomonas elastase binds to endogenous $\alpha_{2}$-macroglobulin and that there is specific, time-dependent uptake of pseudomonas elastase by cultured monocytes. Finally, uptake of pseudomonas elastase is blocked by antibody to the receptorbinding domain of $\alpha_{2}$-macroglobulin.

Other physiologic factors are likely to have an impact on proteolytic activity at sites of tissue injury and on the ability of the host to respond to destructive metallo-enzymes of bacterial or endogenous origin. First, other exogenous and endogenous proteinases may cleave $\alpha_{1}$-AT in the same region. A metalloproteinase secreted by mouse macrophages $(9,10)$, a human neutrophil-derived metalloenzyme $(11,14)$, and thiol-protease cathepsin L (12) are examples. Second, reactive oxygen intermediates may also have the same net effect as pseudomonas elastase. Oxidation of the reactive site $\mathrm{Met}^{358}$ of $\alpha_{1}$-AT renders the inhibitor susceptible to cleavage at the $\mathrm{Met}^{358}-\mathrm{Ser}^{359}$ bond by serine proteinase without complex formation $(4,6,8)$. Third, a secondary influx of neutrophils into the site of injury may be anticipated, especially because elastase- $\alpha_{1}$-AT complexes and proteolytically inactivated $\alpha_{1}$-AT possess potent chemoattractant properties $(44,45)$. Fourth, other endogenous inhibitors, produced locally by mononuclear phagocytes and fibroblasts and diffusing from the blood stream into peripheral tissues, may dramatically affect proteolytic activity during the host response to inflammation and tissue injury.

Acknowledgments. The authors thank Dr. Barbara Iglewski for supplying pseudomonas elastase, Dr. Lars Sottrup-Jensen for $\alpha_{2^{-}}$ macroglobulin, and Dr. Fred van Leuven for antibody to the ligand binding domain of $\alpha_{2}$-macroglobulin. We also thank Dr. Harvey R. Colten for critical review and Joyce L. Thomas for secretarial assistance.

\section{REFERENCES}

1. Perlmutter DH, Pierce JA 1989 The alpha-1-antitrypsin gene and emphysema. Am J Physiol 257:L147-L162

2. Travis J, Salvesen G 1983 Human plasma proteinase inhibitors. Annu Rev Biochem 52:655-709

3. Carp H, Janoff A 1978 Possible mechanism of emphysema in smokers: in vitro suppression of serum elastase inhibitory capacity by fresh cigarette smoke and its prevention by antioxidant. Am Rev Respir Dis 118:617-621

4. Carp H, Janoff A 1979 In vitro suppression of serum elastase inhibitory capacity by reactive oxygen species generated by phagocytosing polymorphonuclear leukocytes. J Clin Invest 63:793-797

5. George PM, Vissers MCM, Travis J, Winterbourn CC, Carrell RW 1984 A genetically engineered mutant of $\alpha_{1}$-antitrypsin protects connective tissue from neutrophil damage and may be useful in lung disease. Lancet 2:14261428

6. Hubbard RC, Ogushi F, Fells GA, Cantin AM, Jallat S, Courtney M, Crystal RG 1987 Oxidants spontaneously released by alveolar macrophages of cigarette smokers can inactivate the active site of $\alpha_{1}$-antitrypsin rendering it ineffective as an inhibitor of neutrophil elastase. J Clin Invest 80:1289-1295

7. Lieberman J 1976 Elastase, collagenase, emphysema and alpha-1-antitrypsin deficiency. Chest 70:62-67

8. Ossanna PJ, Test ST, Matheson NR, Regiani S, Weiss SJ 1986 Oxidative regulation of neutrophil elastase-alpha-1 proteinase inhibitor interactions. J Clin Invest 72:1939-1951

9. Banda MJ, Clark EJ, Werb, Z 1980 Limited proteolysis by macrophage elastase inactivates human $\alpha_{1}$-proteinase inhibitor. J Exp Med 152:1563-1570
10. Banda MJ, Clark EJ, Werb Z 1985 Regulation of alpha-1-proteinase inhibitor function by rabbit alveolar macrophages: evidence for proteolytic rather than oxidative inactivation. J Clin Invest 75:1758-1762

11. Desrochers PE, Weiss SJ 1988 Proteolytic inactivation of alpha-1-proteinase inhibitor by neutrophil metallo-proteinase. J Clin Invest 81:1645-1650

12. Johnson DA, Barrett AJ, Mason RW 1986 Cathepsin L inactivates $\alpha_{1}$-proteinase inhibitor by cleavage in the reactive site region. J Biol Chem 261:1474814751

13. Morihara K, Tsuzuki H, Oda K 1979 Protease and elastase of Pseudomonas aeruginosa: inactivation of human plasma $\alpha_{1}$-proteinase inhibitor. Infect Immun 24:188-193

14. Vissers MCM, George PM, Bathurst IC, Brennan SO, Winterbourn CC 1988 Cleavage and inactivation of $\alpha_{1}$-antitrypsin by metalloproteinases released from neutrophils. J Clin Invest 82:706-711

15. Sottrup-Jensen L $1989 \alpha_{2}$-macroglobulin: structure, shape and mechanism of proteinase complex formation. J Biol Chem 64:1 1539-11542

16. Perlmutter DH, May LT, Sehgal PB 1989 Interferon $\beta_{2}$ /interleukin 6 modulates synthesis of $\alpha_{1}$-antitrypsin in human mononuclear phagocytes and in human hepatoma cells. J Clin Invest 84:138-144

17. Barbey-Morel C, Pierce JA, Campbell EJ, Perlmutter DH 1987 Lipopolysaccharide modulates the expression of $\alpha_{1}$-proteinase inhibitor and other serine proteinase inhibitors in human monocytes and macrophages. J Exp Med 16:1041-1054

18. Perlmutter DH, Travis J, Punsal PI 1988 Elastase regulates the synthesis of its inhibitor, $\alpha_{1}$-proteinase inhibitor, and exaggerates the defect in homozygous PiZZ $\alpha_{1}$ PI deficiency. J Clin Invest 81:1774-1780

19. Perlmutter DH, Punsal PI 1988 Distinct and additive effects of elastase and endotoxin on expression of $\alpha_{1}$-proteinase inhibitor in mononuclear phagocytes. J Biol Chem 263:16499-16503

20. Perlmutter DH, Gover GI, Rivetna M, Schasteen CS, Fallon RJ 1990 Identification of serpin-enzyme complex (SEC) receptor on human hepatoma cells and human monocytes. Proc Natl Acad Sci USA 87:3753-3757

21. Saulnier JM, Curtil FM, Duclos M-C, Wallach JM 1989 Elastolytic activity of Pseudomonas aeruginosa elastase. Biochim Biophys Acta 995:285-290

22. Heck LW, Morihara K, McRae WB, Miller EJ 1986 Specific cleavage of human type III and IV collagens by Pseudomonas aeruginosa elastase. Infect Immun 51:115-118

23. Heck LW, Morihara K, Abrahamson DR 1986 Degradation of soluble laminin and depletion of tissue-associated basement membrane laminin by Pseudomonas aeruginosa elastase and alkaline protease. Infect Immun 54:149-153

24. Fick RB, Baltimore RS, Squier SU, Reynolds HY 1985 IgG proteolytic activity of Pseudomonas aeruginosa in cystic fibrosis. J Infect Dis 151:589-598

25. Schultz DR, Miller KD 1974 Elastase of Pseudomonas aeruginosa: inactivation of complement components and complement derived chemotactic and phagocytic factors. Infect Immun 10:128-135

26. Morihara $\mathrm{K}$, Isuzuki $\mathrm{H}$, Harada $\mathrm{M}$, Iwata $\mathrm{T} 1984$ Purification of human plasma $\alpha_{1}$-proteinase inhibitor and its inactivation by Pseudomonas aeruginosa elastase. J Biochem 95:795-804

27. Morvat RT, Calabough M, Duval-Jobe C, Parmely MJ 1989 Inactivation of human gamma interferon by Pseudomonas aeruginosa proteases: elastase augments the effects of alkaline protease despite the presence of $\alpha_{2}$ macroglobulin. Infect Immun 57:1668-1674

28. Theander TG, Kharazmi A, Pederson BK, Christensen LD, Tuede N, Poulsen LK, Odum N, Svenson M, Bendtzen K 1988 Inhibition of human lymphocyte proliferation and cleavage of interleukin-2 by Pseudomonas aeruginosa proteases. Infect Immun 56:1673-1677

29. Schad PA, Bever RA, Nicas TI, Leduc F, Hanne LF, Iglewski BH 1987 Cloning and characterization of elastase genes from Pseudomonas aeruginosa. $\mathrm{J}$ Bacteriol 169:2691-2696

30. Perlmutter DH, Cole FS, Goldberger G, Colten HR 1984 Distinct primary translational products from human liver mRNA give rise to secreted and cell-associated forms of complement protein C2. J Biol Chem 259:1038010385

31. Roberts BE, Paterson BM 1973 Effect of translation of tobacco mosaic virus RNA and rabbit globin 6S RNA in a cell-free system from commercial wheat germ. Proc Natl Acad Sci USA 70:2330-2334

32. Laemmli UK 1970 Cleavage of structural proteins during the assembly of the head of bacteriophage $T_{4}$. Nature 227:690-695

33. Reddy VY, Pizzo SV, Weiss SJ 1989 Functional inactivation and structura disruption of human $\alpha_{2}$ macroglobulin by neutrophils and eosinophils. $\mathrm{J}$ Biol Chem 264:13801-13809

34. Chirgwin TM, Przbyla AE, MacDonald RJ, Rutter WJ 1979 Isolation of biologically active ribonucleic acid from sources enriched in ribonuclease. Biochemistry 18:5294-5301

35. Thomas P 1980 Hybridization of denatured RNA and small DNA fragments transferred to nitrocellulose. Proc Natl Acad Sci USA 77:5201-5205

36. Perlmutter DH, Cole FS, Kilbridge P, Rossing TH, Colten HR 1985 Expression of the $\alpha_{1}$-proteinase inhibitor gene in human monocytes and macrophages. Proc Natl Acad Sci USA 82:795-799

37. Hovi T, Mosher D, Vaheri A 1977 Cultured human monocytes synthesize and secrete $\alpha_{2}$ macroglobulin, J Exp Med 145:1580-1589

38. Marynen P, van Leuven F, Cassiman J-J, Van De Berghe H 1981 A monoclonal antibody to a neo-antigen on $\alpha_{2}$ macroglobulin complexes inhibits receptormediated endocytosis. J Immunol 127:1782-1786

39. Barrett AJ, Brown MA, Sayers CA 1979 The electrophoretically "slow" and "fast" forms of the $\alpha_{2}$ macroglobulin molecule. Biochem J 191:401-412

40. van Leuven F, Marynen P, Cassiman J-J, Van den Berghe H 1988 Proteolysis 
of human $\alpha_{2}$ macroglobulin without hydrolysis of the internal thiolesters or expression of the receptor recognition site. J Biol Chem 263:468-471

41. Pratt CW, Church FC, Pizzo SV 1988 In vivo catabolism of heparin cofactor II and its complex with thrombin: evidence for a common receptor-mediated clearance pathway for three serine protease inhibitors. Arch Biochem Biophys 22:111-117

42. Perlmutter DH, Joslin G, Nelson P, Schasteen CS, Adam SA, Fallon RJ 1990 Endocytosis and intracellular degradation of $\alpha_{1}$ antitrypsin-protease complexes is mediated by the SEC receptor. $\mathbf{J}$ Biol Chem 265:16713-16716
43. Twumasi DY, Liener IE, Goldston M, Levytska V 1977 Activation of human leukocyte elastase by human $\alpha_{2}$-macroglobulin. Nature 267:61-63

44. Banda MJ, Rice AG, Griffin GL, Senior RM $1988 \alpha_{1}$-proteinase inhibitor is a neutrophil chemoattractant after proteolytic inactivation by macrophage elastase. J Biol Chem 263:4481-4484

45. Banda MJ, Rice AG, Griffin GL, Senior RM 1988 The inhibitory complex of human $\alpha_{1}$-proteinase inhibitor and human leukocyte elastase is a neutrophil chemoattractant. J Exp Med 167:1608-1615

\section{Announcement}

\section{Annual Meeting of the European Society for Pediatric Research 1991}

The European Society for Pediatric Research (ESPR) will hold its next meeting in Zürich, Switzerland, September 1-4, 1991. The European Society of Pediatric Allergy and Clinical Immunology and the European Society of Magnetic Resonance in Neuropediatrics will join the ESPR. Satellite postgraduate courses and a symposium will be organized by these two societies on September 1 and September 5.

The main topics of the ESPR meeting are: therapeutic interventions in immune-mediated diseases, connective tissue, energy metabolism, and circulation of the neonatal brain.

Deadline for submitting abstracts is April 15, 1991.

For information, contact: Gabriel Duc, University Hospital of Zürich, Frauenklinikstrasse 10, ZH-8091 Zürich, Tel. + 41125553 40, Telefax + 4112554442 . 